\title{
Precipitation hardening and hydrogen embrittlement of aluminum alloy AA7020
}

\author{
SANTOSH KUMAR* and T K G NAMBOODHIRI ${ }^{\dagger}$ \\ Neelachal Ispat Nigam Limited, Bhubaneswar 751 022, India \\ ${ }^{\dagger}$ Department of Metallurgical Engineering, Banaras Hindu University, Varanasi 221 005, India
}

MS received 12 September 2008

\begin{abstract}
AA7020 Al-Mg-Zn, a medium strength aluminium alloy, is used in welded structures in military and aerospace applications. As it may be subjected to extremes of environmental exposures, including high pressure liquid hydrogen, it could suffer hydrogen embrittlement. Hydrogen susceptibility of alloy AA7020 was evaluated by slow strain-rate tensile testing, and delayed failure testing of hydrogen-charged specimens of air-cooled, duplexaged, and water-quenched duplex aged materials. The resistance to hydrogen embrittlement of the alloy was found to be in the order of air-cooled duplex aged alloy > as-received (T6 condition) > water quenched duplex aged material.
\end{abstract}

Keywords. Hydrogen embrittlement; AA7020 Al-Mg-Zn alloy; duplex ageing; delayed failure.

\section{Introduction}

AA7020, a medium strength aluminium alloy, is widely used in welded engineering structural components, military applications and in aerospace applications. In space applications, this material may be subjected to extremes of environmental exposures, including both low and high temperatures, high pressures and highly corrosive and reactive fluids. Many highperformance rocket engines use high pressure liquid hydrogen as fuel. These fluids are particularly difficult to handle at high pressures because of the embrittling effect of hydrogen. The performance characteristics of materials used in such applications depend greatly on various environmental factors, an important one being the susceptibility towards hydrogen.

Aluminium alloys were generally believed to be immune to hydrogen embrittlement. However, it was realized that many high-strength aluminium alloys are prone to environment-assisted cracking, and hydrogen embrittlement could be a possible mechanism for the same. Now there is overwhelming evidence in the literature to the fact that hydrogen embrittlement is involved in the stress corrosion cracking of 7XXX series alloys in aqueous environments (Gest and Troiano 1974; Scamans et al 1976; Kotsikos et al 2000). Loss in tensile ductility at low strain rates (Holroyd and Hardie 1982) and delayed failure (Gruhl and Cordier 1968) have been observed. The stress corrosion cracking resistance of age-hardened $\mathrm{Al}-\mathrm{Zn}-\mathrm{Mg}$ alloys was found to depend upon composition, grain structure, quench rate from the solutionizing temperature, and ageing temperature and time (Kent 1970). The higher the total $\mathrm{Zn}+\mathrm{Mg}$ content,

*Author for correspondence (santosh178@ rediffmail.com) higher will be the susceptibility. Taylor suggested an upper limit of $4 \%$ for $\mathrm{Zn}$ in commercial alloys (Taylor 1963). Importance of the quench rate on resistance to stress corrosion cracking was first reported by Taylor. It was pointed out that many of the early failures in $\mathrm{Al}-\mathrm{Zn}-\mathrm{Mg}$ alloys were due to the rapid quench rates used. In an $\mathrm{Al}-4 \% \mathrm{Zn}-2 \% \mathrm{Mg}$ alloy, the maximum resistance to stress corrosion cracking was observed in a material solution treated and air cooled (cooling rate $=1-2{ }^{\circ} \mathrm{C} / \mathrm{s}$ ). The cracking susceptibility increased with increasing cooling rate. Cold water quenching of these alloys, which produces rates of cooling $>200^{\circ} \mathrm{C} / \mathrm{s}$, results in an unacceptably low resistance to stress corrosion cracking, particularly if the material is fully recrystallized and given a single step ageing. Al alloy with a fine fibrous structure and duplex aged to near peak hardness may tolerate a cold water quenching. An overaged material with a recrystallized structure may also tolerate water quenching (Kent 1970).

Transformation sequence for ageing the 7020 alloys is given as follows (Berg et al 2001):

$$
\begin{aligned}
& \text { Solid solution }(\alpha) \rightarrow \text { GP zone } \rightarrow \eta^{\prime}\left(\mathrm{MgZn}_{2}\right) \\
& \quad \rightarrow \eta\left(\mathrm{MgZn}_{2}\right) .
\end{aligned}
$$

Solutionizing temperature for this alloy is $480-500^{\circ} \mathrm{C}$ for $1-1.5 \mathrm{~h}$. The solutionized alloy is cooled fast to retain the high temperature single phase solid solution $(\alpha)$ at room temperature as metastable supersaturated solid solution (SSSS) and then aged. Ageing is the process of controlled decomposition of SSSS to form finely dispersed precipitates usually at one, and sometimes at two, intermediate temperatures for suitable time period (Berg et al 2001; Wolverton 2001).

The GP zones are coherent with matrix and have spherical shape. The interfacial energy for GP zone in the Al- $\mathrm{Zn}-\mathrm{Mg}$ 
system is so low that a high density of very small size zone $(\sim 30 \AA$ ) can be produced at low temperatures (e.g. $20-120$

$\left.{ }^{\circ} \mathrm{C}\right)$. The semi-coherent intermediate metastable phase $\eta^{\prime}$ has a hexagonal unit cell with $a=4.96 \AA$ and $c=8.68 \AA$ while the incoherent equilibrium phase $\eta \mathrm{MgZn}_{2}(84.32 \% \mathrm{Zn})$ also has hexagonal unit cell with $a=5 \cdot 21 \AA$ and $c=8.6 \AA$ (Berg et al 2001; Wolverton 2001).

The main drawback of precipitation hardening of 7020 aluminium alloy is the formation of a precipitate free zone. To eliminate the formation of a PFZ, 7020 alloy is subjected to a duplex or triplex ageing treatment (Polmear 1981). Duplex ageing process aims at forming a large number of precipitate nuclei at the low temperature stage, when the solid solution is appreciably supersaturated and diffusion process is low. These are then allowed to grow to optimum size at a fast rate by ageing at a second, but higher, temperature. Duplex ageing provides a higher density and greater uniformity of distribution of precipitate than is possible in one-step ageing at an elevated temperature (Wolverton 2001).

Weldable $\mathrm{Al}-\mathrm{Zn}-\mathrm{Mg}$ alloys are generally given either a single-stage ageing at $120^{\circ} \mathrm{C}$ for $24 \mathrm{~h}$ or a duplex ageing to peak hardness at $150^{\circ} \mathrm{C}$. The duplex ageing leads to marginally superior resistance to stress corrosion cracking as compared to that of single-step ageing.

The morphology of precipitation influences the substructure developed in these alloys and thus affects the resistance to environment-assisted fracture (Albrecht et al 1979). In the first place, the fine precipitates within the grains control slip mode by the shearing mechanism. When the particles are sheared by dislocations, planar slip occurs with accompanying low resistance to stress corrosion cracking. If the particles are not sheared, slip will be wavy and stress corrosion cracking resistance will be high. Secondly, the coarser grain boundary precipitates along with the weaker precipitate free zone at the grain boundaries may lead to reduced resistance to stress corrosion cracking. Mechanistically, both features play a role in environmental susceptibility. Slip planarity is important for hydrogen transport, whereas the grain boundary precipitates may act as accumulators of hydrogen.

Hydrogen-induced ductility loss in high strength $\mathrm{Al}$ alloys is a function of microstructure. The loss was largest in underaged condition and smallest in the overaged state. This suggests that the degree of susceptibility to hydrogen embrittlement is strongly related to slip planarity. The coherent GP zones present in underaged materials can be cut by passing dislocations, leading to a local softening of the slip plane, and thus to the formation of concentrated slip bands. In the T6 temper, the matrix contains mixture of GP zones and semi-coherent $\eta^{\prime}$ precipitates. In this condition, the slip distribution is inhomogeneous at low plastic strains, but becomes more and more homogeneous with increasing strain. The correlation between slip distribution and hydrogen sensitivity suggests the possibility that moving dislocations facilitate hydrogen transport in this material. With the low hydrogen diffusivity in aluminium, the observed embrittling effects of hydrogen cannot be explained on the basis of lattice diffusivity. Enhanced transportation of hydrogen by dislocations in aluminium alloys has been reported (Thompson and Bernstein 1980). Enhanced mobility through dislocations alone cannot explain hydrogen embrittlement of Al alloys. Planar slip must be accompanied by the presence of trapping sites where hydrogen could accumulate and cause embrittlement and crack initiation. $\mathrm{Mg}$ segregated to grain boundaries plays a critical role in the hydrogen-induced cracking of Al alloys (Scamans et al 1987). Mg atoms may localize hydrogen entry, accelerate hydrogen transport and/or provide sites for grain boundary embrittlement by hydrogen chemisorption or hydride formation. Cracking was analysed in terms of fracture mechanics, applied to the lenticular flaw loaded by applied stress and the internal hydrogen pressure.

The present study is aimed at evaluating the effect of ageing on the hydrogen susceptibility of AA7020 alloy. The study consisted of (i) ageing behaviour of 7020 alloy at different temperatures, and (b) effect of ageing on the hydrogen embrittlement behaviour of the alloy.

\section{Experimental}

\subsection{Materials}

Medium strength AA7020 Al-Zn-Mg alloy in the form of $44 \mathrm{~mm}$ thick sheets in T6 condition, made at BALCO, India, was supplied by Vikram Sarabhai Space Research Centre (VSSC) of the Indian Space Research Organization. The chemical composition of the material is given in table 1 .

\subsection{Heat treatment}

Samples were cut for metallography, as well as for tensile and delayed failure testing and solutionized at $480^{\circ} \mathrm{C}$ for $1 \mathrm{~h}$ and then air cooled or water quenched. Both air-cooled and water-quenched samples were either natural aged, or, aged at $100^{\circ} \mathrm{C} / 140^{\circ} \mathrm{C} / 160^{\circ} \mathrm{C}$, or, duplex-aged at $100^{\circ} \mathrm{C}$ for $4 \mathrm{~h}$ and $140^{\circ} \mathrm{C}$ for different times.

Table 1. Chemical composition of AA7020 alloy (wt \%).

\begin{tabular}{cccccccccc}
\hline Material & $\mathrm{Zn}$ & $\mathrm{Mg}$ & $\mathrm{Cu}$ & $\mathrm{Si}$ & $\mathrm{Fe}$ & $\mathrm{Mn}$ & $\mathrm{Ti}+\mathrm{Zr}$ & $\mathrm{Cr}$ & $\mathrm{Zr}$ \\
\hline AA7020 & 4.54 & 1.13 & 0.002 & 0.13 & 0.23 & 0.32 & 0.128 & 0.12 & 0.11 \\
\hline
\end{tabular}




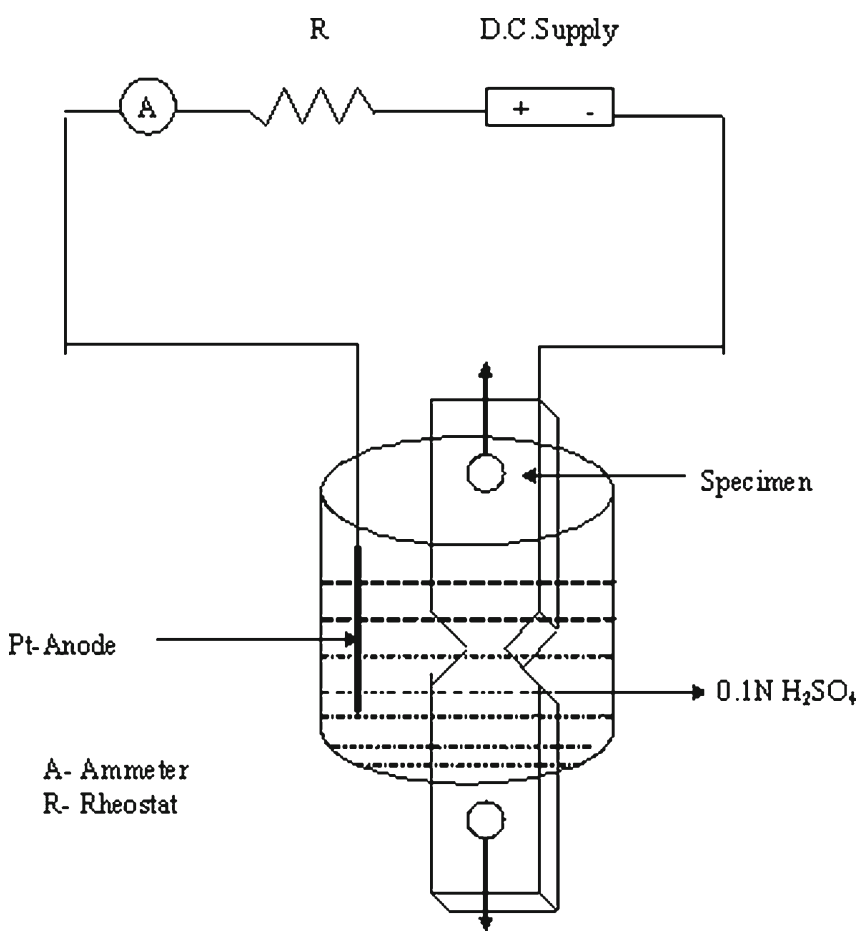

Figure 1. Hydrogen charging cell.

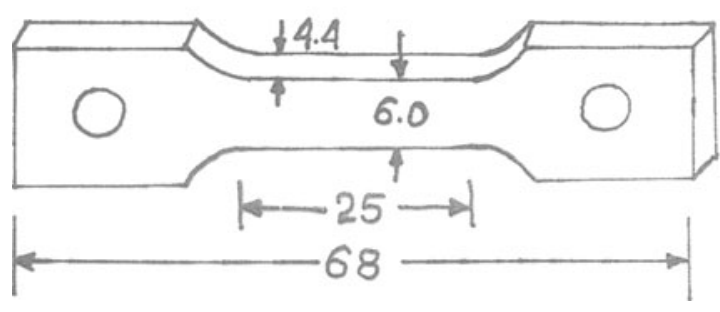

Figure 2. Tensile test specimen.

\subsection{Metallography}

Optical metallography was done using LEITZ, Metallux 3 model projection microscope. For revealing the microstructure, Keller's reagent was used as the etchant.

\subsection{Hydrogen charging}

Specimens were cathodically charged in $0 \cdot 1 \mathrm{~N} \mathrm{H}_{2} \mathrm{SO}_{4}$ solution using a DC power supply. All specimens were initially charged for $96 \mathrm{~h}$ (4 days) at a constant density of $15 \mathrm{~mA} / \mathrm{cm}^{2}$. A schematic view of the hydrogen charging set up is shown in figure 1. Only the notch region of the specimen was charged. Surfaces outside the notch region were coated with enamel to avoid hydrogen charging.

\subsection{Mechanical testing}

A Vickers hardness testing machine was used to measure the hardness of the heat-treated AA7020 alloys. Tensile specimens, of dimensions shown in figure 2 , were tested at two

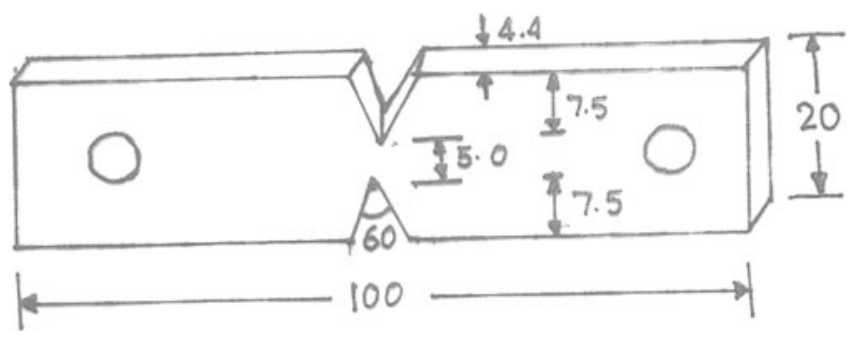

Figure 3. Notch test specimen.

different strain rates $\sim \times 10^{-3} / \mathrm{s}$ and $\sim \times 10^{-5} / \mathrm{s}$. Hydrogen precharged $(96 \mathrm{~h})$ and uncharged tensile specimens were tested to determine the hydrogen embattlement susceptibility of the alloy.

\subsection{Delayed failure test}

Notched sheet specimens (of dimension given in figure 3) were used for delayed failure test. A Maye's Unisteel Stress Corrosion testing machine with a lever ratio of 1:30 was used. This dead-loading machine has a lever-operated microswitch, which shuts off the timer when the specimen fails, thus enabling the measurement of fracture time.

In one set of testing, the specimens were pre-charged with hydrogen for $96 \mathrm{~h}$ and then tested in air. In another set, dead loading and hydrogen charging (in situ) were carried out simultaneously, after pre-charging the specimen for $96 \mathrm{~h}$.

\subsection{Scanning electron fractography}

The fracture surfaces were examined under a JEOL, JSM840A model scanning electron microscope, operating at an accelerator voltage of $10 \mathrm{kV}$.

\section{Results}

\subsection{Age hardening behaviour of 7020 alloy}

Ageing behaviour of 7020 alloy was determined at four different temperatures, i.e. room temperature, $100^{\circ} \mathrm{C}, 140^{\circ} \mathrm{C}$ and $160^{\circ} \mathrm{C}$. All the specimens were initially solution-treated at $480^{\circ} \mathrm{C}$ for $1 \mathrm{~h}$ and then water quenched. The maximum hardness in this alloy was 125-130 VHN irrespective of the ageing temperature. As expected, the maximum hardness was achieved at shorter ageing times as ageing temperature is increased. The maximum hardness was not reached even after $240 \mathrm{~h}$ ageing at room temperature. Figure 4 shows the aging behaviour of 7020 alloys at different temperatures. Figure 5 shows the effect of cooling rate on natural ageing. This shows that ageing kinetics is not significantly affected by the change in cooling rate for room temperature ageing. Figure 6 shows the effect of cooling rate on duplex ageing behaviour of 7020 alloy. It is seen that water quenching leads to a higher maximum hardness than air-cooling and the maximum hardness is achieved after a smaller ageing time. 


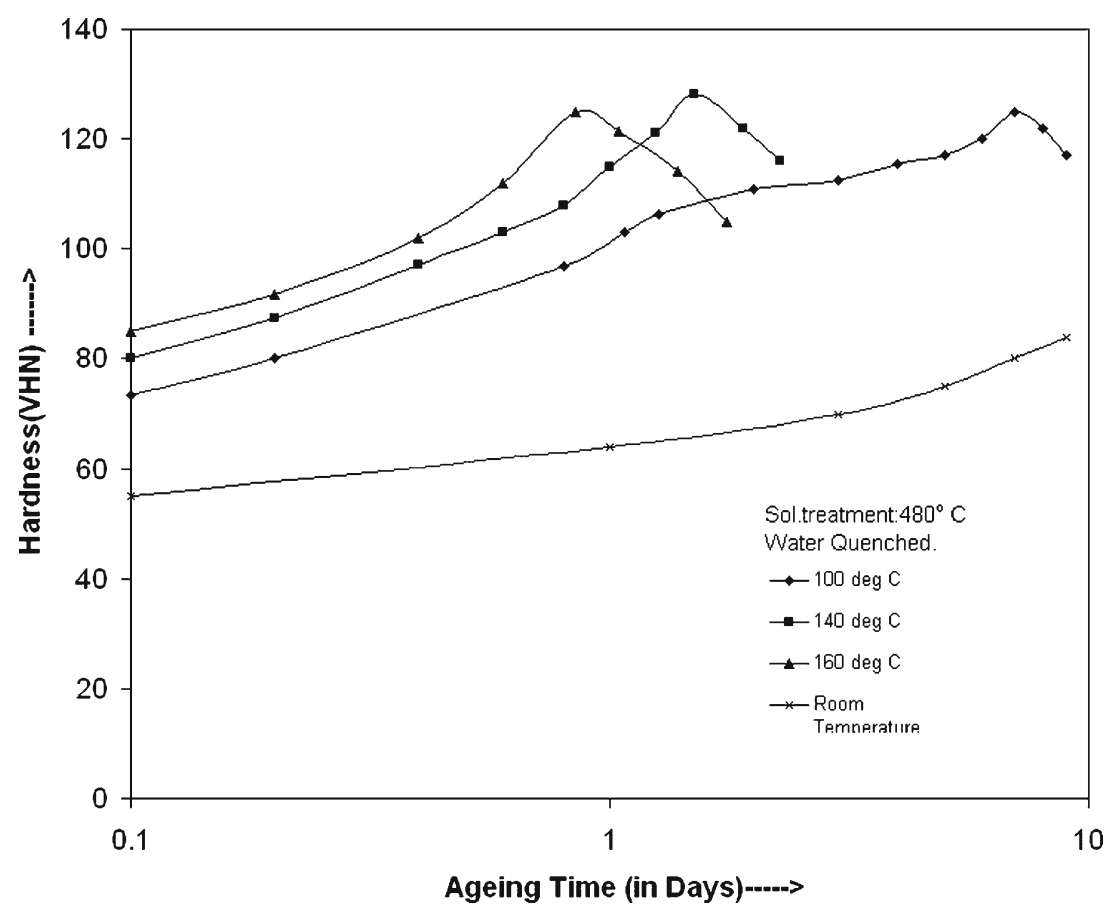

Figure 4. Age hardening behaviour of 7020 alloy.

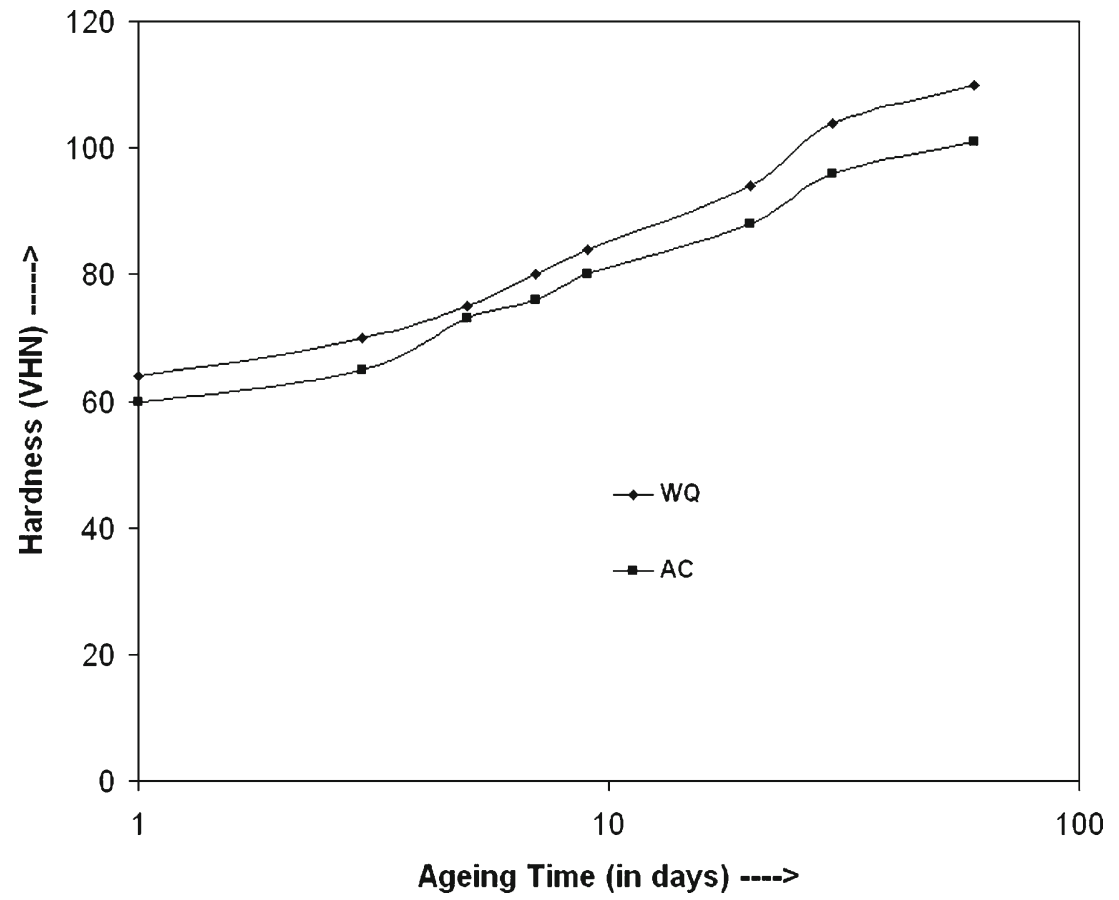

Figure 5. Effect of cooling rate on natural ageing.

\subsection{Material characterization}

Microstructure of the as-received material, given in figure 7(a), shows equi-axed grains, in which fine precipitate particles are dispersed. The precipitate particles generally formed in 7020 alloy are $\mathrm{MgZn}_{2}, \mathrm{Mg}_{2} \mathrm{Si}$, and (Fe, Mn) $\mathrm{Al}_{6}$.
Microstructure of air-cooled and duplex aged material, (figure 7(b)), shows recrystallized equi-axed grains, and precipitate particles dispersed in the matrix and also along the well-defined grain boundaries. Microstructure of water quenched and duplex aged material, (figure 7(c)), shows recrystallized, equi-axed grains of smaller size as compared 


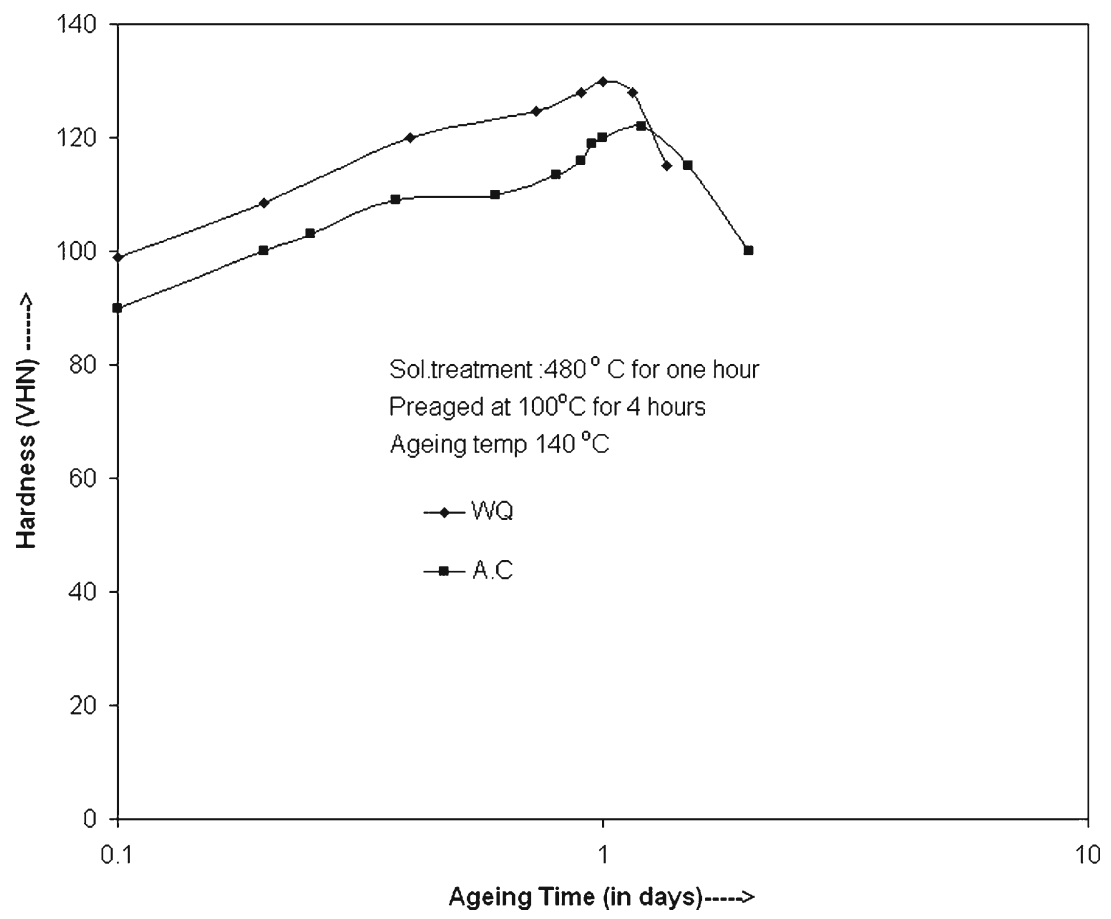

Figure 6. Effect of cooling rate on duplex ageing behaviour of 7020 alloy.
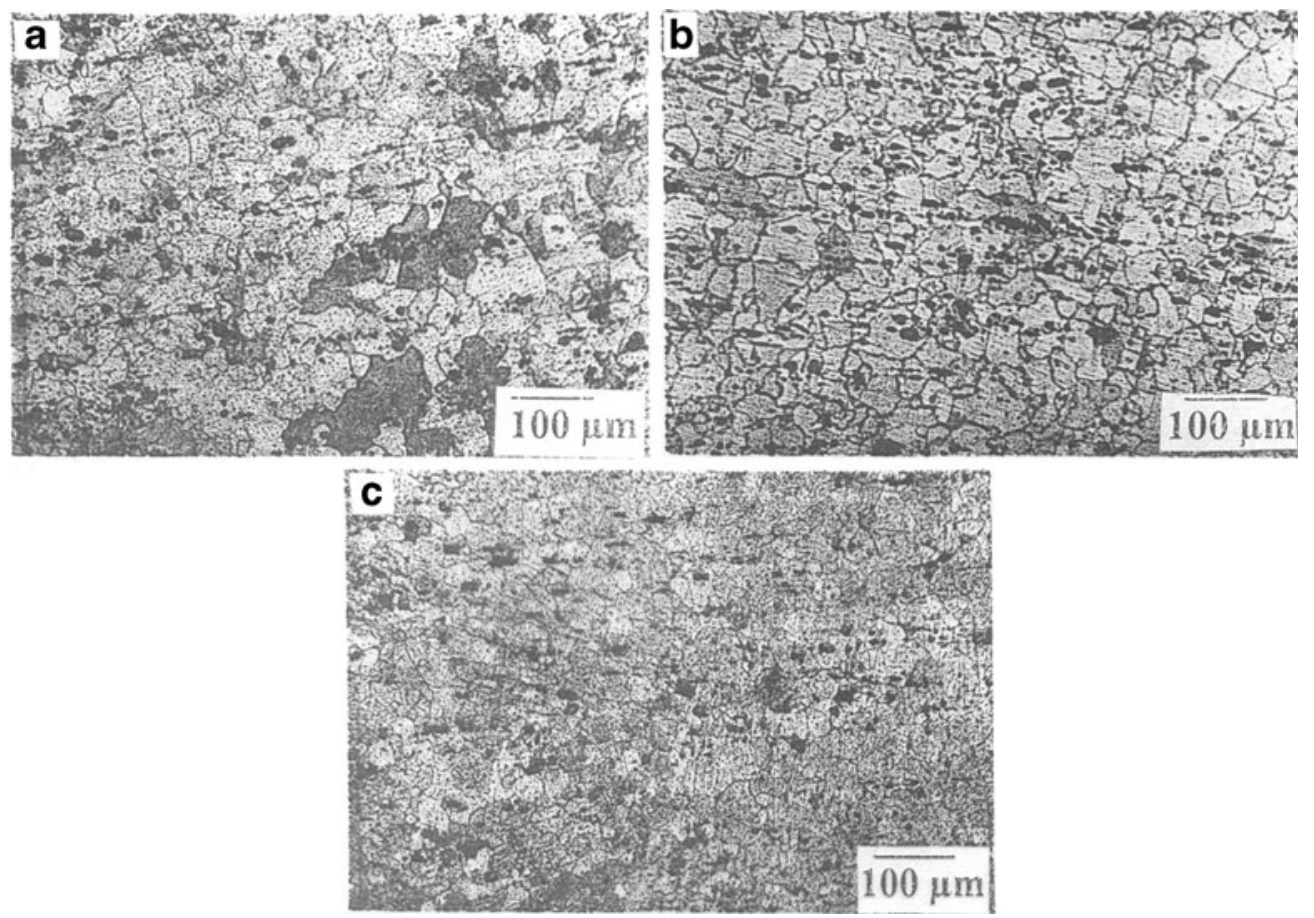

Figure 7. Microstructure of AA7020 alloys: a. as-received (T6 condition), b. air cooled and duplex aged condition and $\mathbf{c}$. water quenched and duplex aged condition.

to those in figures 7(a) and (b). Fine precipitate particles are dispersed in the matrix and thin sheets of a second phase are formed along the grain boundaries. Stress-strain curves for the as-received as well as age-hardened alloys are shown in figure 8.
Table 2 shows mechanical properties of the alloys under three conditions. It is seen that the tensile properties of the as-received, water-quenched, and aged materials, are very close to each other, whereas, the air-cooled and aged materials show some reduction in all the properties. 


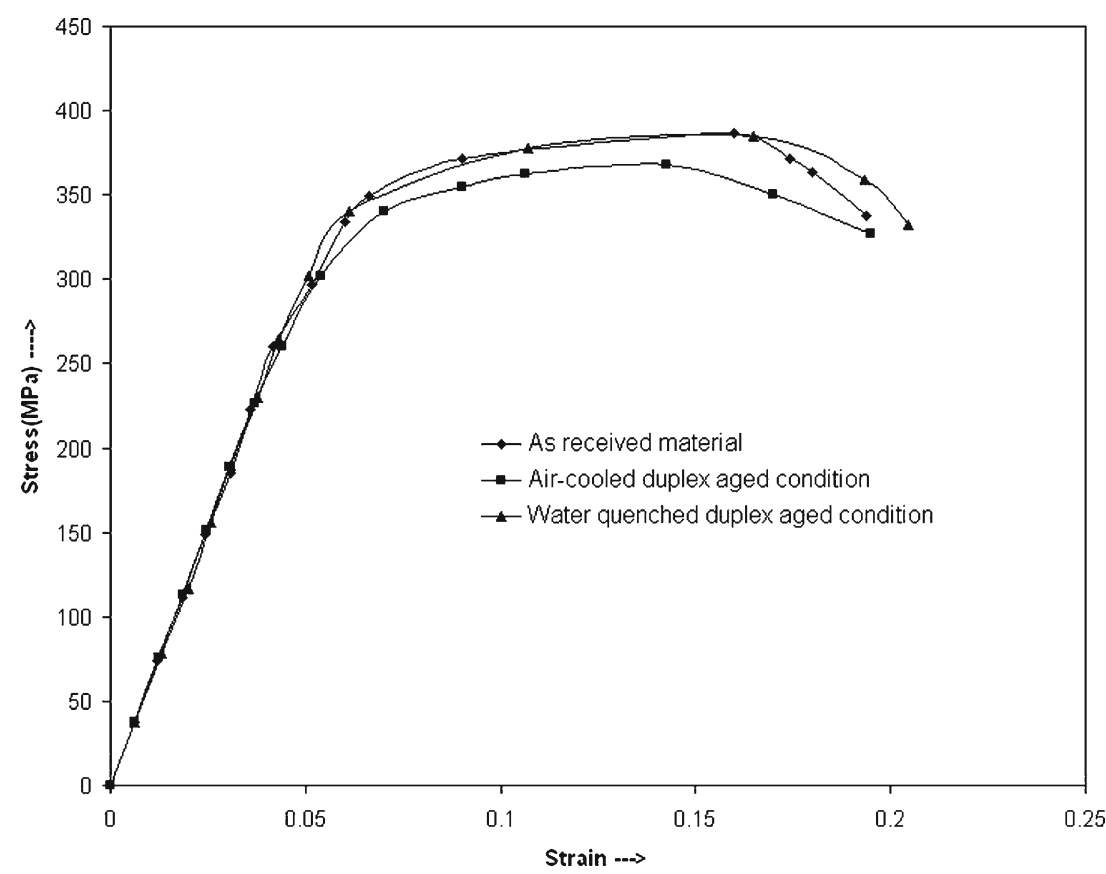

Figure 8. Material characterization: tensile test.

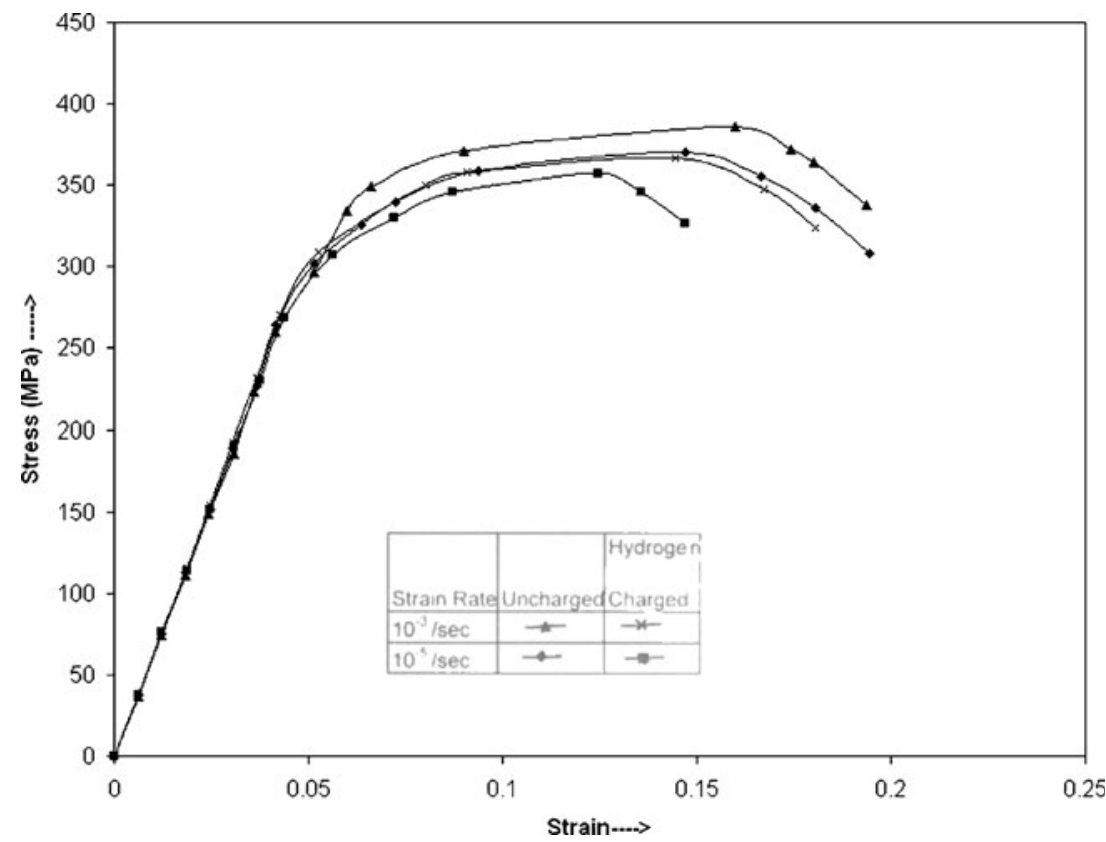

Figure 9. Effect of hydrogen embrittlement on tensile test: as-received material.

Table 2. Mechanical properties of 7020 alloy (strain rate?).

\begin{tabular}{lccccccc}
\hline Heat treatment & YS (MPa) & UTS (MPa) & $\%$ Elongation & $\%$ RA & VHN (kg/mm $\left.{ }^{2}\right)$ & NTS (MPa) & NTS/UTS \\
\hline As-received material & 320 & 386 & $11 \cdot 5$ & $31 \cdot 0$ & 126 & 422 & $1 \cdot 09$ \\
Air-cooled duplex-aged condition & 310 & 368 & $13 \cdot 2$ & $30 \cdot 1$ & 120 & 408 & $1 \cdot 11$ \\
Water-quenched duplex-aged condition & 330 & 385 & $13 \cdot 5$ & $33 \cdot 3$ & 130 & 420 & $1 \cdot 09$ \\
\hline
\end{tabular}


The water-quenched and aged alloy shows higher strength and ductility as compared to those of the air-cooled and aged alloy. Coarser grain size and larger precipitate particles were seen in air-cooled and aged alloy than those of waterquenched and aged alloy (figure 7), leading to lower strength and ductility for the former.

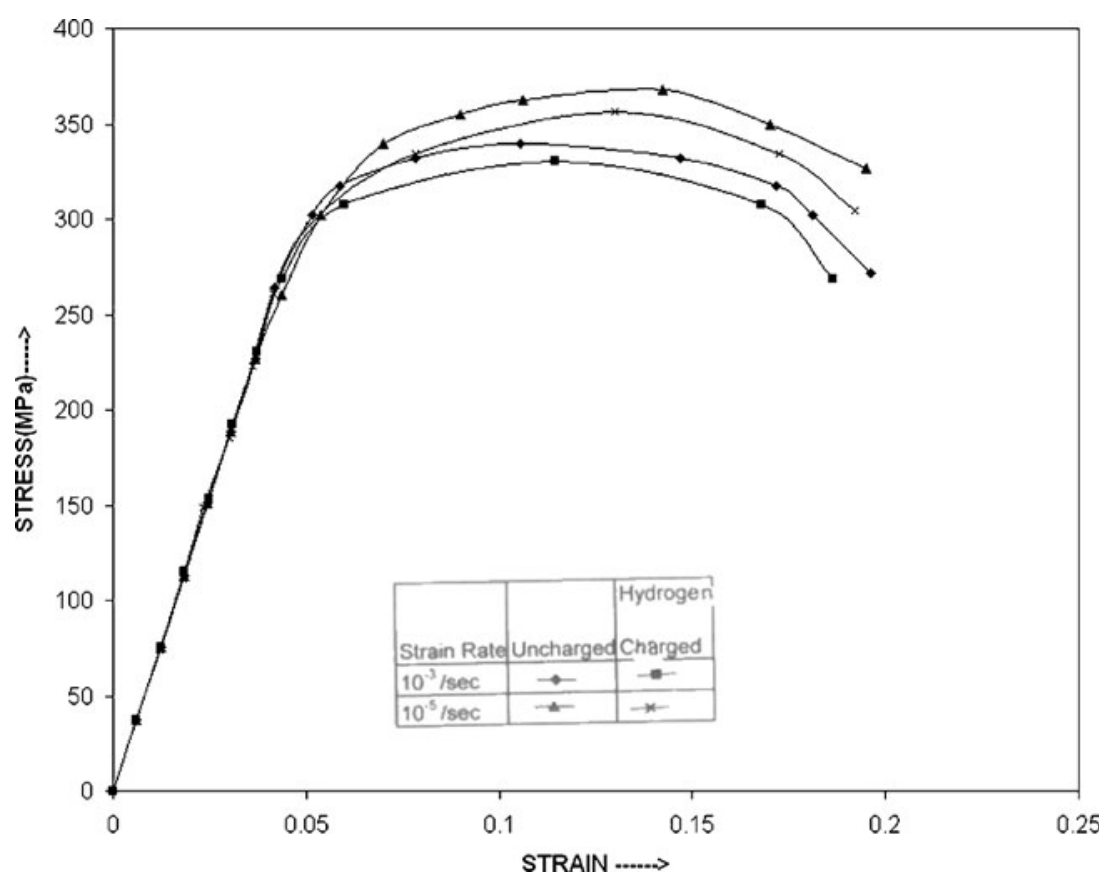

Figure 10. Effect of hydrogen embrittlement on tensile test: air-cooled duplex aged material.

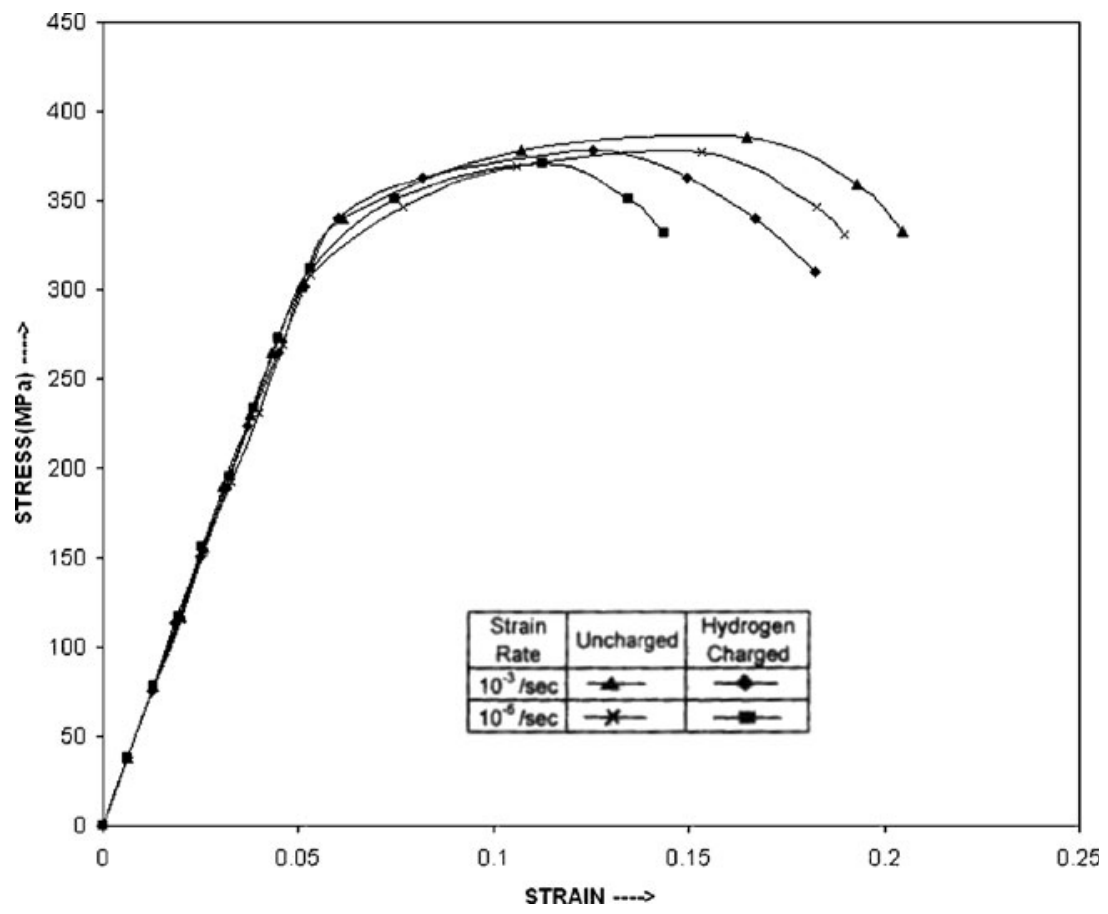

Figure 11. Effect of hydrogen embrittlement on tensile test: water-quenched duplex aged material. 


\subsection{Hydrogen embrittlement of 7020 alloys}

3.3a Effect of strain rate on tensile behaviour: Figure 9 shows the effect of strain rate on tensile behaviour of the as-received material. The two strain rates chosen for test- ing were $10^{-3} \mathrm{~s}$ and $10^{-5} \mathrm{~s}$. Hydrogen charging reduces the UTS and \% elongation of the material at both strain rates. Figure 10 shows the effect of strain rate on tensile behaviour of hydrogen charged and uncharged air-cooled duplex aged materials. Figure 11 shows the effect of strain rate on

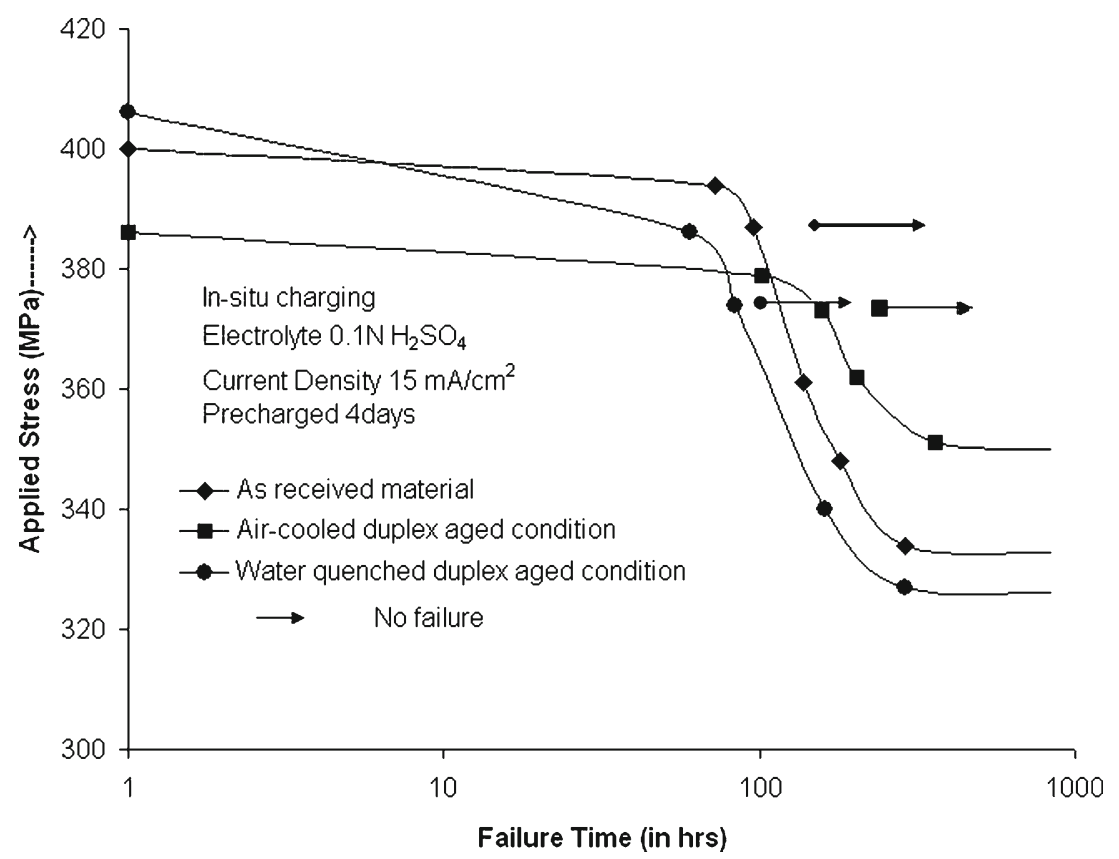

Figure 12. Delayed failure behaviour of AA7020 alloys.
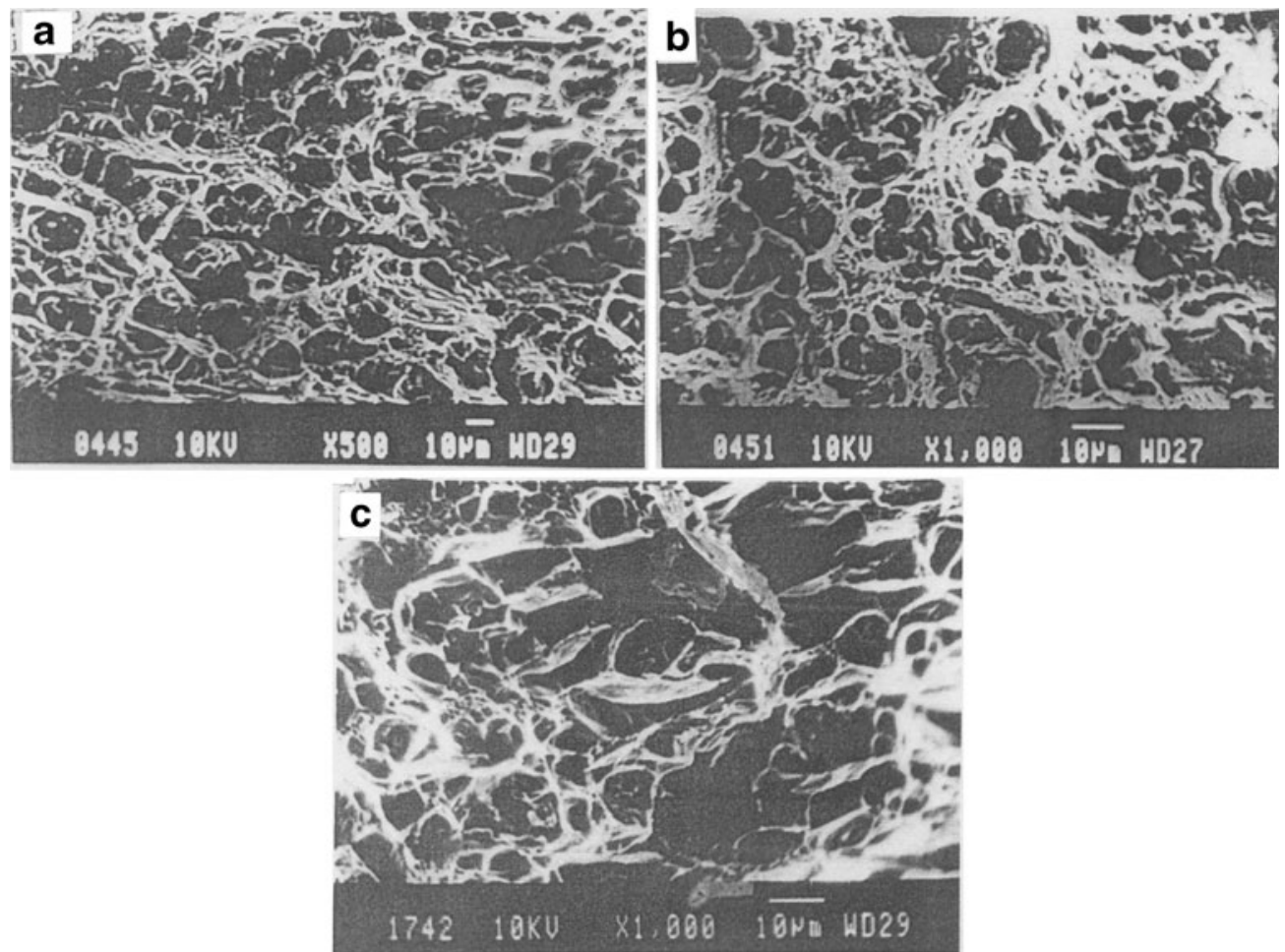

Figure 13. Fracture surfaces of 7020 alloy in uncharged condition (air): a. as-received material, b. air-cooled duplex aged and c. water-quenched duplex aged. 

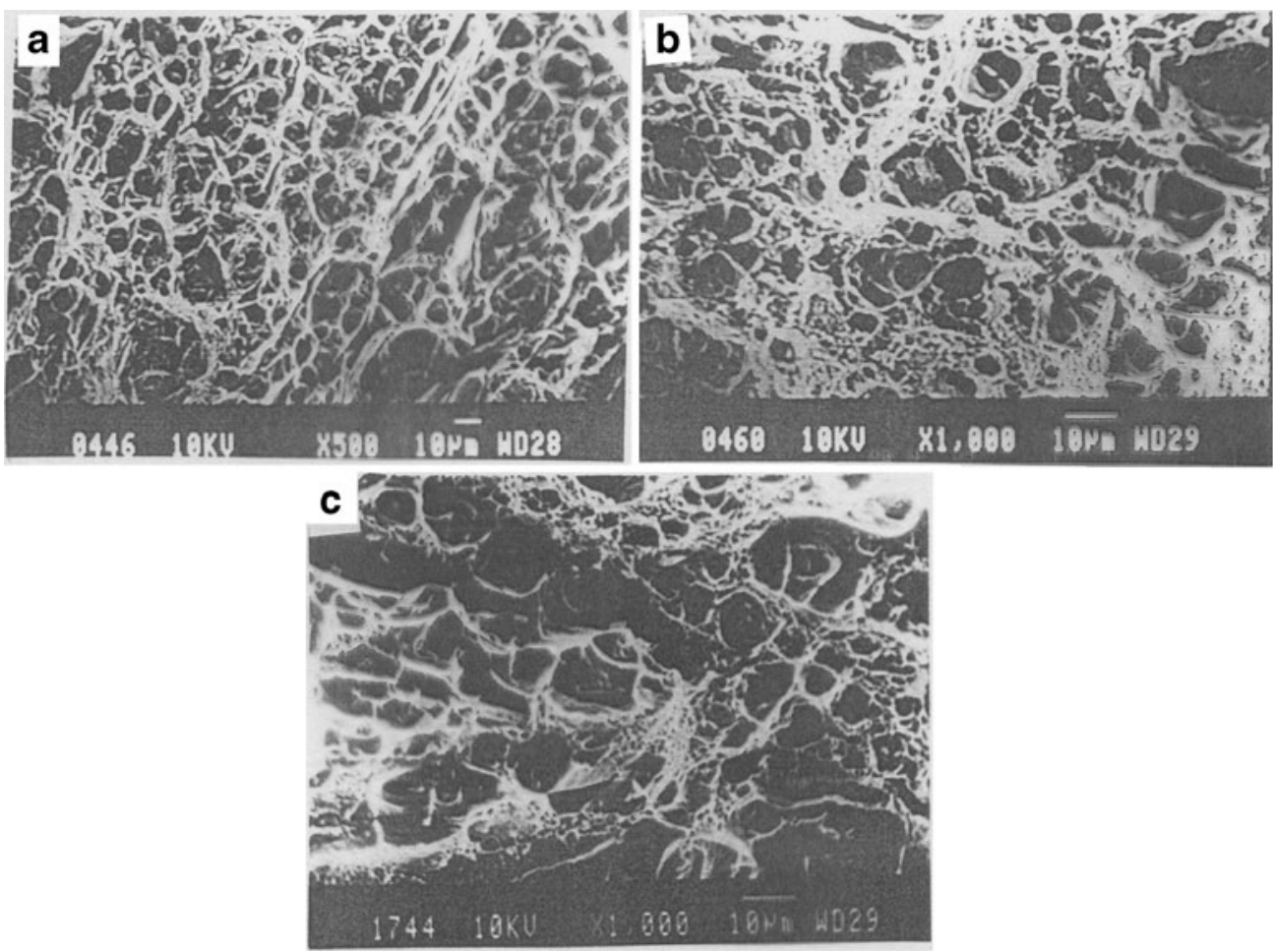

Figure 14. Fracture surfaces of 7020 alloy in hydrogen charged condition: a. as-received material (time of failure $138 \mathrm{~h}$, applied stress, $361 \mathrm{MPa}$ ), b. air-cooled duplex aged (time of failure $92 \mathrm{~h}$, applied stress, $379 \mathrm{MPa}$ ) and c. water-quenched duplex aged (time of failure $60 \mathrm{~h}$, applied stress, $386 \mathrm{MPa}$ ).

tensile behaviour of hydrogen-charged and uncharged water quenched duplex aged materials. These figures show that in general, the decrease in properties is more at the lower strain rate than that at the higher strain rate. The water quenched and aged material shows the maximum change in property at the slow rate $\left(10^{-5} \mathrm{~s}\right)$ and air-cooled and aged material, the least change. Hence the susceptibility to hydrogen embrittlement varies in the following order:

$$
\begin{aligned}
& \text { Water quenched - duplex aged }>\text { as-received (T6) } \\
& \quad>\text { air cooled - duplex aged. }
\end{aligned}
$$

3.3b Delayed failure: Delayed failure curves are plotted in figure 12. It is seen from this figure that at any stress level, time to failure is greater in case of the air-cooled material as compared to those of as-received and water quenched materials. The lower critical stress is found to be the highest in the case of air-cooled material. Lower critical stress varies in the order as shown below:

WQ+Dup A $<$ as received material $<$ air cooled+Dup A.

These results indicate that the water-quenched material is most susceptible to hydrogen.

\subsection{Fractography}

Figure 13 shows the fracture surfaces of as-received, aircooled duplex aged and water-quenched duplex aged alloy, tested in air (uncharged). A ductile micro-void coalescence fracture mode is seen. Some flat facets are also visible in all three samples. Figure 14 shows the fracture surfaces of asreceived, air-cooled duplex aged and water-quenched duplex aged alloy, respectively delayed fracture tested after hydrogen charging. A significant change in the fracture mode is seen in the hydrogen charged materials. In these materials also the predominant fracture mode is ductile micro-void coalescence. Micro-voids usually initiate at inclusions or precipitate particles. Hydrogen may increase the void nucleation sites by enhancing decohesion of precipitate particles from the matrix. The void growth may also be assisted by hydrogen as it accumulates in these voids and exert pressure on the voids. In general, the micro-voids in the hydrogen charged materials are smaller.

\section{Discussion}

The alloy shows classical age hardening behaviour and the maximum hardness values were obtained at shorter ageing times as the ageing temperature increased. Artificial ageing produced the maximum hardness after ageing for 1-10 days as the ageing temperature decreased from $160^{\circ} \mathrm{C}$ to $100^{\circ} \mathrm{C}$, and the maximum hardness was between 120 and $130 \mathrm{VHN}$. Natural ageing did not significantly alter by changes in cooling rate from solutionizing temperature. The water-quenched alloy did give a higher hardness at all times as compared to 
that of the air-cooled sample. The commercial heat treatment given to AA7020 is a duplex ageing in order to avoid susceptibility to stress corrosion cracking. In this study duplex ageing was evaluated in materials water-quenched or air-cooled from solutionizing temperature. The ageing curves given in figure 6 suggest an insensitivity of ageing kinetics on the cooling rate employed. While the water-quenched material showed a higher hardness at all times, the peak hardness was reached after one day's ageing at $140^{\circ} \mathrm{C}$ in both waterquenched and air-cooled materials. The peak hardness value of $120-130$ VHN is the same as that obtained by single-step ageing at these temperatures. However, the air-cooled alloy is expected to have much reduced retained stresses and consequently much less susceptibility to environment assisted fracture. All further studies were conducted on materials duplex aged to peak hardness (1 day's ageing) after water-quenching or air-cooling.

The optical microstructures of the as-received as well as duplex aged materials, shown in figure 7, show a 'pan-cake' grain structure. Both the as-received material as well as the water-quenched duplex aged material showed less recrystallization as compared to the air-cooled and duplex aged material. All three materials showed a dense distribution of globular precipitates, essentially at the grain boundaries and irresolvable fine precipitation within the grains.

Tensile tests conducted on the as-received as well as duplex aged materials indicated that all three materials behave in a similar fashion, but the air-cooled duplex aged material gave somewhat lower strength values as compared to other two materials.

Since hydrogen embrittlement is enhanced by testing at very low strain-rates, tensile tests were performed on the asreceived as well as duplex-aged materials at two strain rates $\left(10^{-3} \mathrm{~s}\right.$ and $\left.10^{-5} \mathrm{~s}\right)$. Tensile properties like yield strength, ultimate tensile strength, $\%$ elongation at fracture and \% reduction in area were measured for uncharged and hydrogen charged specimens (figure 9). These properties exhibited only minor changes after hydrogen charging. The changes seem to be more at the slower strain rate $\left(10^{-5} \mathrm{~s}\right)$ and for the water-quenched and duplex-aged material. But no consistent conclusion could be drawn from these results.

One of the most characteristic features of hydrogen embrittlement is the delayed failure observed in hydrogencharged materials. As seen from figure 12, all the three materials are seen to be susceptible to hydrogen-induced delayed failure. There is an incubation period of about $100 \mathrm{~h}$, the water-quenched-aged material showing the smallest period and the air-cooled-aged material the longest. The lower critical stress, the stress below which hydrogen-induced failure does not occur, changes in the order:

Air-cooled aged $>$ as-received $>$ water quenched-aged.

It is seen that the lower critical stress for the air-cooledaged alloy is about $1 \cdot 1$ times its UTS. A similar trend is also present in the case of applied stress vs notch tensile strength.
From these data it is clear that the hydrogen embrittlement susceptibility decreases in the order:

$$
\begin{gathered}
\text { Air-cooled duplex aged alloy }<\text { as-received } \\
<\text { water quenched duplex aged material. }
\end{gathered}
$$

Microstructurally, the air-cooled aged material is characterized by very wide precipitate free zones and coarse particles of $\mathrm{Mg}-\mathrm{Zn}_{2}$, with large inter-particle distances, on the grain boundaries. The highly susceptible water-quenchedaged material, on the other hand, has narrow PFZ and dense precipitation of $\mathrm{Mg}-\mathrm{Zn}_{2}$ at the grain boundaries. The fractographs clearly show that hydrogen embrittlement has not altered the ductile fracture mode of AA7020 alloy. Hence, the grain boundary embrittlement mechanism proposed for stress corrosion cracking of high strength $\mathrm{Al}-\mathrm{Zn}-\mathrm{Mg}$ alloys may not be applicable in the present case.

A dense distribution of fine precipitates within the matrix grains necessitates a cutting mechanism for dislocations to move, and would lead to planar slip and enhanced susceptibility to hydrogen embrittlement. On the other hand, a coarser precipitation would produce dislocation looping and wavy slip leading to much reduced hydrogen embrittlement. In the air-cooled and duplex-aged material, a coarser precipitation within the grains than that in the water quenchedduplex aged material may be expected. If it is so, the present results may be explained on the basis of the difference in the substructure of the two materials. Further electron microscopic studies will be required to confirm this explanation.

\section{Conclusions and suggestions for future study}

The major conclusions drawn from the present study are the following:

(I) AA7020 aluminium alloy is susceptible to hydrogen embrittlement.

(II) Its susceptibility to hydrogen embrittlement changes with the ageing treatment given. Resistance to hydrogen embrittlement changes in the order:

$$
\begin{aligned}
& \text { Air cooled-duplex aged }>\text { as-received (T6) } \\
& >\text { water quenched-duplex aged. }
\end{aligned}
$$

(III) Explanation of the mechanism of embrittlement and its microstructure dependence requires further transmission electron microscopic study of the state of precipitation within the grains in the duplex-aged materials and the development of sub-structure upon deformation.

\section{References}

Albrecht J, Thompson A W and Bernstein I M 1979 Metall. Trans. A10 1759 
Berg L K, Gjonnes J, Hansen V, Li X Z, Knutson-wedel M, Waterloo G, Schryvers D and Wallenberg R 2001 Acta Mater. 49 3443

Gest R J and Troiano A R 1974 Corrosion 30274

Gruhl W and Cordier D 1968 Aluminium 44403

Holroyd N J H and Hardie D 1982 Proc. 3rd int. congress on hydrogen and materials (ed) P Azou (Paris: ISMCM) Vol. 2, p. 659

Kent K G 1970 Metals and Materials 4429

Kotsikos G, Sutcloff J M and Holroyd N J H 2000 Corr. Sci. 4217
Polmear I J 1981 Light alloys: Metallurgy of the light metals (London: Edward Arnold (Publishers) Ltd) pp. 19-84

Reboul M C, Dubost B and Lashermes M 1985 Corros. Sci. 25 999

Scamans G M, Alani R and Swan P R 1976 Corros. Sci. 16443

Scamans G M, Holroyd N J H and Tuck C D S 1987 Corros. Sci. 27 329

Taylor E A 1963 Met. Prog. 8474

Thompson A W and Bernstein I M 1980 Advances in corrosion science and technology (New York: Plenum Press) Vol. 7, p. 53

Wolverton C 2001 Acta Mater. 493129 